\title{
Vertrauen auf Infarktmelder aus dem Labor
}

\author{
Zur wirksamen Vorbeugung von Herzinfarkten könn- \\ te mehr getan werden - und das schonend, meint \\ Kardiologe Dr. Klaus Edel. Er nutzt bei seiner Arbeit \\ daher spezielle Blutwerte als wichtiges Prognosemit- \\ tel. Eine Top-Ten-Idee beim Praxispreis 2015!
}

Weniger Herzinfarkte und Rezidive sind möglich, da ist sich Edel sicher. Er war Ärztlicher Direktor der Reha-Klinik Hochstaufen in Bayerisch Gmain, leitete dort die Kardiologie und Angiologie. Seit Jahren beschäftigt ihn, dass Infarktpatienten nicht immer die passende Therapie erhalten. So werde zu wenig berücksichtigt, dass nicht verkalkte Plaques in Blutgefäßen das Hauptproblem seien, sondern noch nicht verkrustete Fettseen, die aufreißen könnten. „Wenn eine Arterie zu 50\% verengt ist, wobei wir Kardiologen nach den aktuellen Leitlinien nicht interventionell eingreifen dürfen, besteht das höchste Herzinfarktrisiko." Schon Mitte der 1990er las Edel dazu eine Studie von Falk et al.. Viel zu wenig, sagt er, sei das berücksichtigt worden. Statt dessen beobachte er allzu große Katheter-Begeisterung. „Die Zahl der Herzkatheter in Deutschland liegt weit über dem Schnitt in der EU. Wenn die Katheterei so gut wäre, müsste es bei uns die wenigsten Patienten geben, die nach der Behandlung einen Herzinfarkt haben. "Sein Fazit: „Diese ständigen Wiedereinbestellungen für Herzkatheter bei beschwerdefreien Patienten nach Koronarintervention sind völlig sinnlos.“

Er selbst nutzt eine Diagnostik, die auf spezielle Blutwerte abzielt. „Die Fettseen in den Arterien versuche ich derzeit über Labormethoden zu finden, und die Patienten dazu zu bringen, sie durch Lebensstiländerung selbst aufzulösen.“ Die Möglichkeiten solcher Laborwerte würden zu wenig ausgeschöpft. „Bisher messen Ärzte das LDL-Cholesterin. Aber der Wert sagt nichts darüber, wie viel Fett in der Arterienwand ist. Daher erfasse ich auch den hs-CRP-Wert. Ist er hoch, muss der Mensch Fettseen haben. „Hs-CRP steht für hoch sensitives cardioreaktives Protein, das die Leber bei Entzündungen freisetzt. Seit etwa 10 Jahren erhebt Edel diesen Wert zusätzlich bei ca. 5\% der jährlich 2000 von ihm wegen entsprechender Herzkrankheiten Behandelten. Bei ihnen gehe er davon aus, dass sie eine Lebensstiländerung u.a. im Sinne von ausgewogener Ernährung und Bewegung nach aktuellen Empfehlungen anstreben. Sei eine Lebensstiländerung nicht zielführend, müssten zusätzlich Medikamente helfen, z.B. Statine.

Mit seiner Idee zählte Edel zu den 10 Bestplatzierten beim Wettbewerb „Die innovative Arztpraxis 2015“. Die Schwierigkeit beim hs-CRP-Wert sei v.a. seine umstrittene Spezifität und Sensitivität mit widersprüchlichen Studienergebnissen. Edel meint, das liege an einer suboptimalen Probandenauswahl. Denn: Gebe es im Körper andere Entzündungen, sei der hsCRP-Wert nicht aussagekräftig bzgl. Arterienverfettung. Sei man sonst aber entzündungsfrei, sei der prognostische Wert seiner Erfahrung nach gut. Um Messprobleme zu verringern, erfasst der Arzt zuerst das weniger reaktionsintensive CRP. Ist es niedrig, nimmt er Entzündungsfreiheit an und nutzt den hsCRP-Wert als Indikator. Und: „Derzeit erhebe ich neu den LpPLA2-Wert für die Bestimmung der Festigkeit von Ablagerungen. Das ist ein Eiweiß, das unbeeinflusst von Entzündungen im Körper aus Gefäßplaques freigesetzt wird. Je instabiler eine Ablagerung, desto höher der Lp-PLA2-Wert." Edel sucht weiter nach Infarkt-Warnern. Seit Kurzem tut er das am Herz-Kreislaufzentrum in Rotenburg a.d. Fulda.

Christina Bauer

\section{Bewerbungsfrist bis 31.12.2016 verlängert!}

Seit 5 Jahren loben UCB Innere Medizin und die Fachverlagsgruppe Springer Medizin, zu der auch „Info Diabetologie“ gehört, unter dem Namen „Die innovative Arztpraxis“ den Praxis-Preis für Ärzte mit Ideen für eine bessere Versorgung und/oder für eine effiziente Praxisführung aus. Haben Sie eine Idee umgesetzt, die Ihnen hilft, den Praxisalltag zu verbessern?

Haben Sie sich Gedanken gemacht, wie Sie Ihre Patienten strukturiert versorgen können? Wissen Sie, wie sich die Kommunikation im Praxis-Team oder mit anderen Praxen oder Einrichtungen optimieren lässt? Dann machen Sie mit beim diesjährigen Wettbewerb „Erfolgs-Rezept - der Praxis-Preis 2016“! Ärzte und ihre Praxisteams können noch bis zum 31. Dezember mitmachen.

Die Bewerbung erfolgt online: Unter www.aerztezeitung.de/erfolgsrezept finden Sie ein Formular, auf dem Sie Ihre Idee und deren Umsetzung kurz beschreiben können.
Die drei Gewinnerteams stellen im Hause von Springer Medizin in Berlin ihre Konzepte persönlich vor. $\mathrm{Zu}$ gewinnen gibt es außerdem einen dreitägigen Ausbildungslehrgang mit Abschluss „Geprüfte Assistenz für Versorgung und Prävention" von der Unternehmensberatung HCC Better Care GmbH, Köln, sowie Buchpreise von Springer Medizin und HCC. (ger/mh)

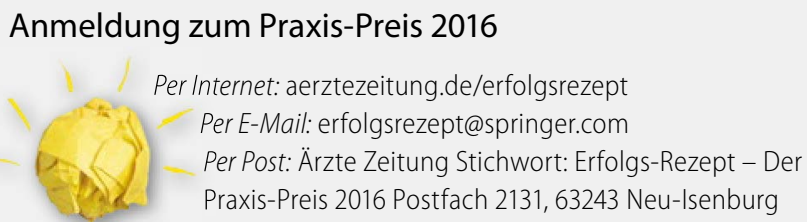

